\title{
Myocardial infarction related to coronary artery bypass graft surgery
}

\author{
C G A MCGREGOR, ^ A L MUIR, A F SMITH, H C MILLER, W J HANNAN, E W J CAMERON, \\ D J WHEATLEY†
}

From the Departments of Clinical Surgery, Medicine, Clinical Chemistry, and Medical Physics, University of Edinburgh, and the Departments of Cardiology and Cardiac Surgery, Royal Infirmary, Edinburgh

\begin{abstract}
SUMMARY Fifty consecutive patients undergoing coronary artery bypass grafting for chronic stable angina were assessed by serial electrocardiography, preoperative and postoperative myocardial scanning with technetium-99m pyrophosphate, gated radionuclide ventriculography, and serial measurement of creatine kinase, aspartate aminotransferase, urea stable lactic dehydrogenase, and creatine kinase isoenzyme (MB) to assess the incidence of perioperative myocardial infarction and identify the most appropriate diagnostic techniques. The correlation between myocardial scanning and the measurement of peak enzyme and isoenzyme activity was excellent in the diagnosis of perioperative infarction, although electrocardiography proved less helpful. There appeared to be no advantage in measuring creatine kinase $M B$ rather than the more routinely measured enzymes. There were two deaths and evidence of myocardial infarction in five other patients, an incidence of $14 \%$. Perioperative infarction was associated with a significant reduction in resting ejection fraction in two cases. In those patients without evidence of perioperative infarction the mean increase in ejection fraction of $\mathbf{7 \cdot 8 \%}$ was statistically significant.
\end{abstract}

Myocardial infarction related to coronary artery bypass graft surgery is associated with increased mortality and morbidity and accounts for most deaths perioperatively and within the first month of operation. ${ }^{1}$ The incidence of this complication is difficult to estimate, and figures of $4-40 \%$ have been reported. ${ }^{2-4}$ The varying incidence can be attributed to variations in operative expertise, techniques of myocardial protection, case selection, and particularly to the diagnostic indices of myocardial infarction applied in different series. ${ }^{5-7}$

The assessment of chest pain and interpretation of the electrocardiogram in the diagnosis of myocardial infarction after cardiac surgery are difficult. ${ }^{8-10}$ An increase in the activity of enzymes, including the rela-

Requests for reprints to Dr C G A McGregor, Department of Cardiovascular Surgery, Stanford University School of Medicine, Stanford University Medical Center, Stanford, California 94305, USA.

^Present address: Department of Cardiovascular Surgery, Stanford University School of Medicine, Stanford University Medical Center, Stanford, CA 94305, USA.

†Present address: Department of Cardiac Surgery, University of Glasgow, Royal Infirmary, Glasgow.

Accepted for publication 27 October 1983 tively cardiospecific MB isoenzyme of creatine kinase (CKMB), occurs after cardiac surgery, and the ability of plasma enzyme measurements to distinguish those patients who have had a myocardial infarction related to coronary surgery remains uncertain. ${ }^{11^{-13}}$ Other diagnostic techniques include radionuclide imaging with technetium-99m pyrophosphate, which in a non-surgical context is a sensitive and specific indicator of myocardial infarction. ${ }^{14} 15$ Furthermore, this technique may be the only method of making the diagnosis after coronary surgery in some patients. ${ }^{16-18}$

Severe myocardial infarction is likely to be associated with impairment of left ventricular function, and a comparison of left ventricular performance before and after operation using radionuclide ventriculography is a further method of assessing myocardial injury.

In the present study the above techniques were used in 50 patients undergoing coronary artery bypass surgery. Our aim was to identify the most appropriate techniques for diagnosing perioperative myocardial infarction. Once the incidence of perioperative infarction and the most accurate methods of diagnosis have been determined, the effect of improved methods of 
myocardial preservation may be assessed.

\section{Patients and methods}

Fifty consecutive patients undergoing coronary artery bypass graft surgery as the sole procedure were studied. All underwent operation for the treatment of chronic stable angina uncontrolled by optimum medical treatment. All patients were being treated with beta blockers. Their age range was 36-68 (mean 52) years.

\section{OPERATIVE TECHNIQUES}

Standard cardiopulmonary bypass techniques were used at flow rates of $2.41 / \mathrm{m}^{2}$. The mean bypass time was 114 minutes (range 53-224 minutes), and the mean aortic cross clamping time 36 minutes (range $0-72$ minutes). The mean number of grafts performed was $2 \cdot 1$ per patient (range $1-4$ ). Intermittent aortic cross clamping with systemic hypothermia to $28^{\circ} \mathrm{C}$ was used in 24 patients and cold potassium cardioplegic arrest with topical cardiac cooling and systemic hypothermia to $28^{\circ} \mathrm{C}$ in 26 . The method of myocardial protection used was based on the current practice of the surgeon performing the operation.

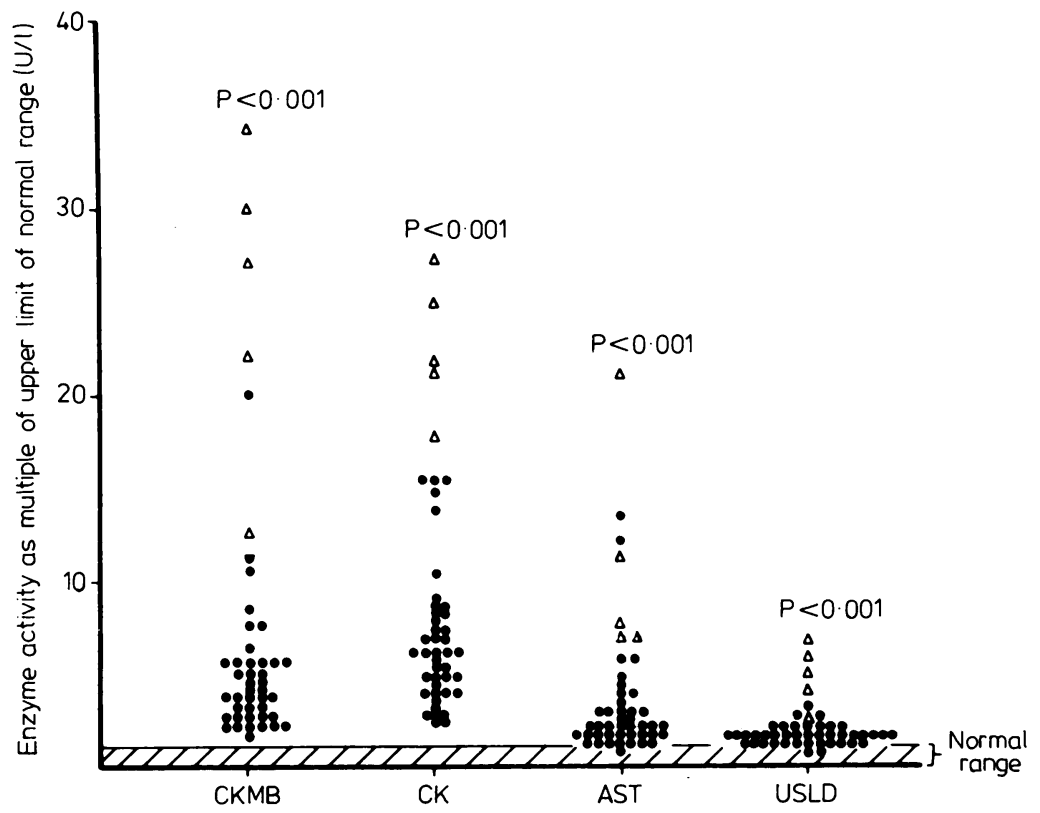

Fig. 1 Peak serum enzyme activities (expressed as a multiple of the upper limit of normal) for creatine kinase $M B(C K M B)$, creatine kinase $(C K)$; aspartate aminotransferase $(A S T)$, and urea stable lactate dehydrogenase (USLD).

$\triangle$, patients with both positive myocardial scan and positive enzyme activity; $\bullet$, remainder of patients. $p$ values refer to comparison of individual enzyme isoenzyme activities between five patients with both positive myocardial scans and positive enzymes/isoenzyme activity and the remaining patients.

\section{ELECTROCARDIOGRAPHY}

Electrocardiograms were recorded preoperatively and daily postoperatively until discharge and were assessed blind by a cardiologist. The appearance of new $Q$ waves of $0.04 \mathrm{~s}$ or more duration was regarded as indicating myocardial infarction.

\section{ENZYME MEASUREMENT}

Creatine kinase and aspartate aminotransferase were measured by standard techniques. ${ }^{19}$ The upper limit of normal for non-ambulant healthy subjects is $\mathbf{1 5 0}$ $\mathrm{U} / 1$ and $30 \mathrm{U} / 1$ respectively.

Creatine kinase $M B$ was measured using a slight modification of the chromatographic method of Mercer ${ }^{20}$ using kit reagents supplied by Boehringer Corporation, Lewes. The upper limit of normal for non-ambulant healthy subjects is $10 \mathrm{U} / 1$.

Urea stable lactate dehydrogenase was measured using a slight modification of a previously published method. ${ }^{21}$ The upper limit of normal for healthy adults is $300 \mathrm{U} / 1$.

Analytical precision was $5 \%$ (coefficient of variation) for enzyme activities for each enzyme in the ranges encountered in this study. The above enzymes were measured preoperatively and on seven subse- 
quent occasions in the first $\mathbf{4 8}$ hours postoperatively: immediately and at $3,6,9,12,24$, and 48 hours after operation.

\section{STATISTICAL ANALYSIS OF DATA}

The definition of a normal response of plasma enzyme activity to coronary artery surgery is difficult. Fig. 1 shows that of the peak measurements for each enzyme a few were higher than the rest. To obtain an objective but, purely arbitrary, definition of normal and abnormal increases in enzyme activity, the following procedure was adopted for each enzyme:

(1) All enzyme values were log transformed (since even the central and left hand portions of the frequency distribution curves showed a log normal rather than a normal distribution).

(2) The central symmetrical portion of the distribution curve (trimmed) was used to yield provision estimates of mean and standard deviation (SD). ${ }^{22}$

(3) Means and standard deviations for each enzyme were calculated using all enzyme measurements except for those which were more than 2 SD above the trimmed mean (from (2)).

Any enzyme measurement more than 2 SD above the mean was classed as being abnormally high. This figure was $109 \mathrm{U} / \mathrm{l}$ for creatine kinase MB, $2600 \mathrm{U} / \mathrm{l}$ for creatine kinase, $190 \mathrm{U} / \mathrm{l}$ for aspartate aminotransferase, and $800 \mathrm{U} / 1$ for urea stable lactate dehydrogenase.

\section{MYOCARDIAL SCANNING}

Analogue and digital images were obtained two hours after an intravenous injection of $400 \mathrm{MBq}(10.8 \mathrm{mCi})$ of technetium- $99 \mathrm{~m}$ pyrophosphate in the anterior, $30^{\circ}$ and $60^{\circ}$ left anterior oblique, and left lateral projections with the patient supine using a Nuclear Enterprises Mk $5 \mathrm{HR}$ gamma camera.
Forty eight patients who were available for study had scans performed between two and five days postoperatively, and in 34 patients scans were also performed preoperatively. All scans were assessed blind by two observers and were graded into: $(a)$ those showing no activity $(-),(b)$ those showing increased activity over the region of the heart but of less intensity than surrounding bone $( \pm)$, and $(c)$ those with increased activity over the heart of equal or greater intensity than bone ( + ). Only category (c) was accepted as a true positive for myocardial infarction and had to be present in two of the four views.

\section{RADIONUCLIDE VENTRICULOGRAPHY}

Radionuclide ventriculography was carried out preoperatively and one week postoperatively at rest in 34 of the 50 patients. All studies were carried out with patients supine using a $30^{\circ}$ left anterior oblique projection with a $10^{\circ}$ caudal tilt on a Nuclear Enterprises Mk 5 HR gamma camera. The method of analysis has been described in detail elsewhere. ${ }^{23}$

\section{Results}

All 34 preoperative technetium myocardial scans were negative. Preoperative enzyme activity was not appreciably increased in any of the 50 patients. Two deaths occurred in the immediate postoperative period of low cardiac output. Both patients were considered to have suffered myocardial injury at the time of operation which was incompatible with maintaining circulation. Of the 48 patients surviving operation, 36 had no evidence of myocardial infarction when any of the criteria used in the study were applied.

Table 1 shows the results for the remaining 12 patients who had evidence of myocardial infarction by at least one criterion. Table 2 summarises the positive

Table 1 Evidence of myocardial infarction in 50 patients after coronary artery bypass graft(s) using technetium-99m pyrophosphate scanning, electrocardiography, and enzyme measurements

\begin{tabular}{|c|c|c|c|c|c|c|}
\hline \multirow[t]{2}{*}{ Case No } & \multirow[t]{2}{*}{ Myocardial scanning } & \multirow[t]{2}{*}{ Electrocardiography } & \multicolumn{4}{|c|}{ Ensyme activity } \\
\hline & & & $C K M B$ & $C K$ & $A S T$ & $U S L D$ \\
\hline 1 & + & + & + & + & + & + \\
\hline 2 & + & + & + & + & + & - \\
\hline 3 & + & - & + & + & + & + \\
\hline 4 & \pm & - & - & - & - & - \\
\hline 5 & - & + & - & - & - & - \\
\hline 6 & - & + & - & - & - & + \\
\hline 7 & + & - & + & + & + & + \\
\hline 8 & - & - & + & - & - & - \\
\hline 9 & - & + & - & - & - & - \\
\hline 10 & + & + & + & + & + & + \\
\hline 11 & - & - & + & - & - & - \\
\hline 12 & - & - & - & - & + & - \\
\hline
\end{tabular}

CKMB, creatine kinase MB; AST, aspartate aminotransferase; USLD, urea stable lactate dehydrogenase; - , negative; + , positive; \pm , scans showing increased activity over the region of the heart but of less intensity than surrounding bone. 
Table 2 Summary of results of myocardial scanning, measurement of ensyme activity, and electrocardiography in 12 patients with evidence of myocardial infarction after coronary artery bypass grafting

\begin{tabular}{|c|c|c|c|c|c|c|}
\hline & \multicolumn{5}{|c|}{ No of positive results } & \multirow[t]{3}{*}{$E C G$ changes } \\
\hline & \multirow[t]{2}{*}{ Scans } & \multicolumn{4}{|l|}{ Ensymes } & \\
\hline & & CKMB & $A S T$ & USLD & Total & \\
\hline \multirow{2}{*}{$\begin{array}{l}\text { Myocardial scans } \\
\text { Electrocardiographic } \\
\text { changes } \\
\text { Enzyme measurements }\end{array}$} & 5 & 5 & 5 & 4 & 5 & 3 \\
\hline & $\begin{array}{l}3 \\
5\end{array}$ & 3 & 3 & 3 & $\begin{array}{l}3 \\
6\end{array}$ & $\begin{array}{l}6 \\
4\end{array}$ \\
\hline
\end{tabular}

CK, creatine kinase; AST, aspartate aminotransferase; USLD, urea stable lactate dehydrogenase.

findings of the diagnostic tests used. In Tables 2 and 3 the results in those patients with isolated increases in activity of only one enzyme and in whom there was no evidence of infarction by any other criterion were omitted.

Five patients had positive myocardial scans. All five had enzymatic evidence of infarction in at least three of the four enzyme measurements including creatine kinase MB isoenzyme. Three of the five patients fulfilled the electrocardiographic criterion of infarction. One further patient had a scan of diffuse appearance (giving a \pm result) which did not correlate with the other criteria.

Six patients had electrocardiographic changes indicating myocardial infarction, but in only three (the same three as above) did this correlate with scanning and enzymatic evidence of infarction. Six patients had enzymatic evidence of myocardial infarction. Five of these patients had positive scans. Four of the patients had positive electrocardiographic evidence, but in one (case 6) the enzymatic evidence consisted of an isolated increase in urea stable lactate dehydrogenase activity.
Table 3 outlines the changes in resting ejection fraction during the operative period in those patients with evidence of infarction. Of the five patients with both scanning and enzymatic evidence of infarction, the ejection fraction remained the same in three and decreased by 0.1 and 0.18 in the remaining two patients, the greatest reductions in the entire group. In the two patients in this group with negative electrocardiograms the ejection fraction decreased by $0 \cdot 1$ in one and was the same in the other $(+0.01)$. The mean reduction in ejection fraction in these patients was $12 \cdot 1 \%$, although this was not statistically significant compared with the preoperative value in this small group of patients. In the two patients with isolated positive creatine kinase $M B$ activity and a negative scan and negative electrocardiogram ejection fraction increased by 0.1 and 0.12 respectively. In the two patients with positive electrocardiograms and both negative scan and negative enzyme/isoenzyme activity ejection fraction increased in one and was the same in the other. In the one patient with a positive electrocardiogram and isolated positive urea stable lactate dehydrogenase activity ejection fraction was

Table 3 Changes in resting ejection fraction assessed by radionuclide ventriculography in 11 patients with evidence of infarction by myocardial scanning, measurement of enzymatic activity, and electrocardiography

\begin{tabular}{|c|c|c|c|}
\hline Case No & Before surgery & After surgery & Change \\
\hline $\begin{array}{r}1 \\
2 \\
3 \\
7 \\
10\end{array}$ & $\begin{array}{l}0.49 \\
0.49 \\
0.4 \\
0.38 \\
0.59\end{array}$ & $\begin{array}{l}\text { ositive enzyme } \\
0.5 \\
0.45 \\
0.41 \\
0.28 \\
0.41\end{array}$ & $\begin{array}{l}+0.01 \\
-0.04 \\
+0.01 \\
-0.1 \\
-0.18\end{array}$ \\
\hline $\begin{array}{r}8 \\
11\end{array}$ & $\begin{array}{l}0.53 \text { Positive } \\
0.4\end{array}$ & $\begin{array}{l}\text { ative scans, an } \\
0.63 \\
0.52\end{array}$ & $\begin{array}{l}+0.1 \\
+0.12\end{array}$ \\
\hline $\begin{array}{l}5 \\
9\end{array}$ & $\begin{array}{ll} & \text { Positive } \\
0.4 & \\
0.4 & \end{array}$ & $\begin{array}{l}\text { s, and negative } \\
0.52 \\
0.44\end{array}$ & $\begin{array}{l}+0.12 \\
+0.04\end{array}$ \\
\hline \multicolumn{4}{|c|}{ Positive enryme (USLD) activity, positive ECG, and negative scan } \\
\hline \multicolumn{4}{|c|}{ Equivocal scan, negative ECG, negative enryme activity } \\
\hline
\end{tabular}




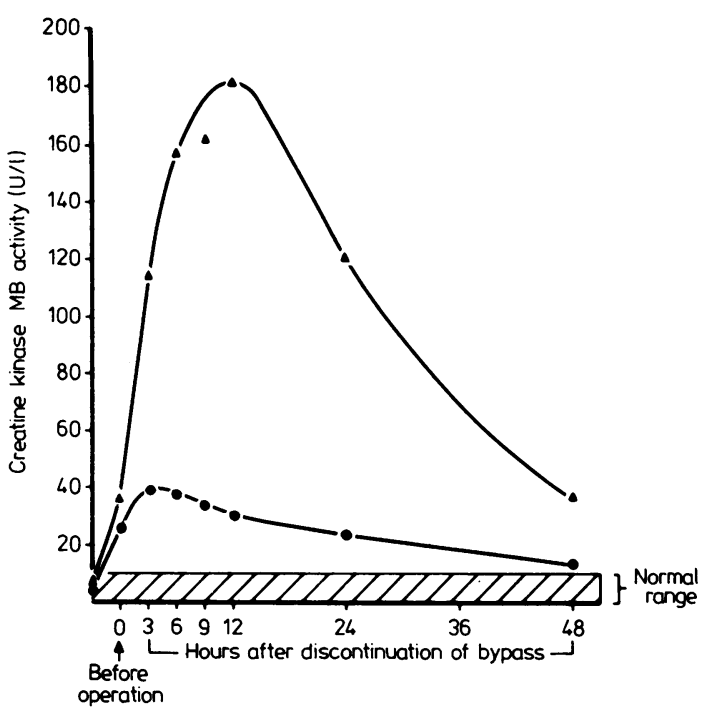

Fig. 2 Mean (geometric) activity of creatine kinase MB at various times in the postoperative period for patients with infarcts (A) and those without (O).

reduced by 0.06 . When the five patients with positive scans and positive enzymes are excluded, there was a significant mean increase in ejection fraction in the remaining patients of $7.8 \%$ in relation to preoperative values $(p<0.05)$. Improved detection of wall motion abnormalities by phase analysis may be helpful in diagnosing perioperative infarction, but this method was not available to us at the time of the study.

Measurements of activity of each of the four enzymes in the five patients with both positive scans and positive enzymes were compared with those in the remaining patients using the Mann-Whitney $U$ test of ranking (Fig. 1). There was no difference between the enzymes in their ability to differentiate between these five patients and the remainder. The timing as well as the magnitude of creatine kinase $\mathrm{MB}$ release were different in these five patients compared with those in the remaining patients (Fig. 2). Peak creatine kinase $M B$ release occurred between nine and 12 hours after operation in these five patients but at about three hours in the others. Only creatine kinase MB has this notable qualitative difference in the shape of the release curve.

There was no significant difference between these five patients with positive myocardial scans and positive enzymes and isoenzymes activity and the remainder of the group in age, cross clamping time, cardiopulmonary bypass time, number of coronary grafts performed, or, with one exception, length of stay in hospital.

\section{Discussion}

Myocardial infarction after coronary artery bypass graft surgery may result from early graft closure, technical failure, or embolisation from the site of anastomosis or from global myocardial ischaemia secondary to cross clamping at the aorta and inadequate myocardial protection. Coronary artery surgery can, therefore, result in myocardial injury which varies in both magnitude and type-that is, whether transmural or global or a mixture of both.

Coronary surgery may improve left ventricular function by restoring circulation to ischaemic myocardium but if complicated by perioperative myocardial infarction may compromise left ventricular function. A balance of the two effects may be present in any individual patient. For this reason we performed ventriculography. Our own observations in non-surgical myocardial infarction 2425 and that of others $^{26-28}$ suggest that, although left ventricular ejection fraction may fluctuate in the acute stages $(0-24 \mathrm{~h})$ of myocardial infarction, cardiac performance thereafter changes little but, in general, gradually improves over the next three to six months. As the patients in the present study were haemodynamically stable without taking any positive inotropic agent at the time of either ejection fraction determination it was appropriate to image at this time and use the observation to correlate with the other diagnostic criteria of severe myocardial injury.

The likelihood of one particular test yielding a positive diagnosis will depend on whether the infarction is transmural or global and on the diagnostic threshold applied to that test. Transmural infarction is more likely to result in a positive electrocardiogram and myocardial scan than a more diffuse lesion, whereas measurements of increased enzyme and isoenzyme activity should be obtained in both. There is, therefore, no clinical gold standard for the diagnosis of perioperative myocardial infarction. In this study the criteria for a positive scan were set high purposefully to avoid false positive results, but by doing this we may have missed very small infarcts. Although we attempted to be objective, the enzymatic and isoenzymatic criteria of infarction are (as discussed) arbitrary.

In this study a good correlation was found between radionuclide scintigraphic and enzymatic and isoenzymatic evidence of myocardial injury. All five patients with positive myocardial scans had enzymatic and isoenzymatic evidence of injury. Agreement between the positive scanning and positive enzymatic criteria applied in the study was regarded as diagnostic of myocardial infarction, and, therefore, these five patients were considered to have had an infarction.

In two of these patients infarction was associated 
with a pronounced reduction in resting ejection fraction as assessed non-invasively by radionuclide ventriculography. In three patients there was little change in ejection fraction, and this is consistent with reports questioning the functional importance of perioperative infarction in some patients. ${ }^{29} 30$ Nevertheless, in two cases perioperative infarction resulted in a pronounced deterioration in cardiac function with a reduced ejection fraction, and in one case the patient was in hospital for three months because of low cardiac output and subsequent renal failure. In the other four patients with myocardial infarction hospital stay was not prolonged. These results agree with those of previous reports showing early and late reduction in ventricular function in patients who have had a perioperative myocardial infarction. ${ }^{31} 32$ In contrast, those patients in the study who were not considered to have had a perioperative infarction had a significant increase in ejection fraction of $\mathbf{7 . 8 \%}$. It is difficult to assess how much the withdrawal of beta blockade affected the postoperative measurement of ejection fraction, but some effect was present in patients both with and without infarcts. In the two patients with isolated isoenzymatic evidence of infarction and negative enzymes, a negative myocardial scan, and negative electrocardiogram no functional deterioration occurred, and the results support the findings of others that isoenzyme activity may be too sensitive in assessing perioperative myocardial infarction when used alone. ${ }^{33} 34$ The one patient with an equivocal ( \pm result) scan had a diffuse increase in uptake over the precordium, which was of lower intensity than that in surrounding bone, and the importance of this appearance is uncertain. ${ }^{6}{ }^{15}$ Patients without coronary disease may show such an appearance. Simultaneous measurement of perioperative enzyme activity helps to elucidate this problem. There were no positive preoperative scans, and this may reflect the fact that our patients had chronic stable angina. Provided that agreement between scanning and enzymatic evidence is accepted as proof of myocardial infarction, in this study there were no false positive scans, which is similar to the results of other workers. ${ }^{133}$ Such patients with chronic stable angina do not seem to need to be studied preoperatively in contrast to other groups of patients-that is, those with unstable angina, in whom the incidence of positive preoperative scans may be as high as $40 \% .{ }^{16} 35$

The measurement of peak isoenzyme activity proved to be a valuable adjunct to myocardial scanning in this study and has been shown to correlate well with other indices of myocardial injury, but its sensitivity and relative advantages over the more commonly measured enzymes are unclear. ${ }^{336} 37$ An important aspect of our study was the finding that there was no advantage in measuring creatine kinase
MB isoenzyme rather than the more routinely measured enzymes. For our laboratory we suggest that measurements of creatine kinase total of $2600 \mathrm{U} / 1$, aspartate aminotransferase of $190 \mathrm{U} / 1$, and urea stable lactate dehydrogenase of $800 \mathrm{U} / 1$ represent myocardial infarction, although the frequency and timing of sampling must be taken into account. These findings will vary for different types of cardiac operations and between centres. The time of peak activity of creatine kinase $M B$ in this study differed between patients with and without infarcts, being nine to 12 hours after operation in those with infarcts and three hours in those without. For routine purposes, it is difficult to justify the requirement for measuring creatine kinase MB.

The electrocardiogram was positive in three of the five patients with scanning and isoenzymatic evidence of injury. Of the other three patients who developed new $Q$ waves, their appearance was transitory in two and persisted in one. These findings are consistent with previous reports of $Q$ waves which do not persist and false positives which have been attributed to unmasking of old infarcts by restoring a normal circulation to an ischaemic contralateral ventricular wall. ${ }^{38}$ $Q$ waves also occur in patients in whom an improvement in regional wall motion in the relevant area has been observed, ${ }^{39}$ although others have found no evidence that the appearance of new $Q$ waves was not due to myocardial infarction. ${ }^{31}$

Many surgical considerations may affect the incidence of perioperative myocardial infarction. In this study both techniques of myocardial protection were used in the group with an infarction. There was one death and one infarct in patients in whom cold cardioplegia was used and one death and four infarcts in the group who had aortic cross clamping with systemic hypothermia. In the present study there was no relation between the incidence of perioperative myocardial infarction and cardiopulmonary bypass times or number of coronary grafts performed, which agrees with some previous reports ${ }^{4041}$ but contrasts with others. ${ }^{30} 42$

As well as resulting in an increase in operative mortality perioperative myocardial infarction has been shown in a recent report from the Coronary Artery Surgery Study ${ }^{42}$ to result in a significant reduction in the three year cumulative survival rate. In that study perioperative infarction was diagnosed by the development of new postoperative $Q$ waves, and these workers acknowledge that this may represent an underestimate of the true incidence. Accepting that the concordance of scanning and enzymatic evidence is indicative of myocardial infarction, the incidence of perioperative infarction in the current study was $14 \%$, including the two patients who died in the immediate postoperative period. It is crucial to estimate the inci- 
dence of perioperative myocardial infarction in order to assess the early and late results of coronary artery surgery and to allow surgeons to monitor the effectiveness of currently used methods of myocardial protection. The combination of myocardial scanning and the measurement of enzyme activity can give a high degree of accuracy in this sometimes difficult diagnostic problem.

This study was carried out with the support of research grants from the Lothian Health Board and Scottish Hospital Endowment Research Trust.

\section{References}

1 DePuey EG, Mathur V, Hall RJ, Burdine JA. Infarct induced wall motion abnormalities in aortocoronary bypass patients. Correlation with electrocardiographic, enzymatic and scintigraphic diagnostic criteria. Cardiovascular Diseases, Bulletin of the Texas Heart Institute 1980; 7: 382-96.

2 Mundth ED, Austen WG. Surgical measures for coronary heart disease. $N$ Engl $\mathcal{F}$ Med 1975; 293: 75-80.

3 Fennell WH, Chua KG, Cohen L, et al. Detection, prediction and significance of perioperative myocardial infarction following aortocoronary bypass. $\mathcal{F}$ Thorac Cardiovasc Surg 1979; 78: 244-53.

4 Bulkley BH, Hutchins GM. Myocardial consequences of coronary artery bypass graft surgery. The paradox of necrosis in areas of revascularization. Circulation 1977; 56: 906-12.

5 Hearse DJ, Braimbridge MV, Jynge P. Protection of the ischaemic myocardium. In: Cardioplegia. New York: Raven Press, 1982: 376-410.

6 Balderman SC, Bhayana JN, Steinbach JJ, Musud ARZ, Michalek S. Perioperative myocardial infarction: a diagnostic dilemma. Ann Thorac Surg 1980; 30: 370-7.

7 Kirklin JW, Conti VR, Blackstone EH. Prevention of myocardial damage during cardiac operations. $N$ Engl f Med 1979; 301: 135-41.

8 Righetti A, Crawford MH, O'Rourke RA, et al. Detection of peri-operative myocardial damage after coronary artery bypass graft surgery. Circulation 1977; 55: 173-8.

9 Kansal S, Roitman D, Kouchoukos N, Sheffield LT. Ischemic myocardial injury following aortocoronary bypass surgery. Chest 1975; 67: $20-7$.

10 Schroeder JS, Alderman EL, Harrison DC. Perioperative myocardial infarction during cardiac surgery: diagnosis, ECG and enzyme testing. Adv Cardiol 1975; 15: $179-84$.

11 Voegele LD, Gross AJ, Prioleau WM, Hairston P. Application of multivariate analysis to the enzyme patterns in the serum of patients undergoing coronary artery operation. Ann Thorac Surg 1980; 29: 444-50.

12 Strom S. Prognostic significance of cardiopulmonary bypass time and postoperative serum enzyme levels in coronary surgery. Scand $\mathcal{F}$ Thorac Cardiovasc Surg 1979; 13: $133-8$.

13 Van der Laarse A, Davids HA, Hollaar L, Van der Valk EJM, Witteveen SAGJ, Hermens WT. Recognition and quantification of myocardial injury by means of plasma enzyme and isoenzyme activities after cardiac surgery. $\mathrm{Br}$ Heart $\mathcal{F}$ 1979; 41: 660-7.

14 Willerson JT, Parkey RW, Bonte FJ, Lewis SE, Corbett J, Buja LM. Pathophysiologic considerations and clinicopathological correlates of technetium $99 \mathrm{~m}$ stannous pyrophosphate myocardial scintigraphy. Semin Nucl Med 1980; 10: 54-69.

15 Lyons, KP, Olson MG, Aronow WS. Pyrophosphate myocardial imaging. Semin Nucl Med 1980; 10: 168-77.

16 Klausner SC, Botvinick EH, Shames D, et al. The application of radionuclide infarct scintigraphy to diagnose peroperative myocardial infarction following revascularization. Circulation 1977; 56: 173-81.

17 Burdine JA, DePuey EG, Orzan F, Mathur VS, Hall RJ. Scintigraphic, electrocardiographic, and enzymatic diagnosis of perioperative myocardial infarction in patients undergoing myocardial revascularization. $7 \mathrm{Nucl} \mathrm{Med}$ 1979; 20: 711-9.

18 Righetti A, O'Rourke RA, Schelbert H, et al. Usefulness of pre-operative and postoperative $\mathrm{Tc} 99 \mathrm{~m}$ (Sn) pyrophosphate scans in patients with ischemic and valvular heart disease. Am f Cardiol 1977; 39: 43-9.

19 The Committee on Enzymes of the Scandinavian Society for Clinical Chemistry and Clinical Physiology. Recommended method for the determination of creatine kinase in blood. Scand F Clin Lab Invest 1976; 36: 711-23.

20 Mercer DW. Separation of tissue and serum creatine kinase isoenzymes by ion exchange chromatography. Clin Chem 1974; 20: 36-40.

21 Brydon WG, Smith AF. An appraisal of routine methods for the determination of the anodal isoenzymes lactate dehydrogenase. Clin Chim Acta 1973; 43: 361-9.

22 Healy MJR. Outliers in clinical chemistry quality control schemes. Clin Chem 1979; 25: 675-7.

23 Muir AL, Hannan WJ, Sapru RP, Boardman AK, Wraith PK, Brash HM. The effects of isoprenaline, atropine and dobutamine on ventricular volume curves obtained by radionuclide ventriculography. Clin Sci 1980; 58: 357-64.

24 Dewhurst NG, Hannan WJ, Muir AL. Prognostic values of radionuclide ventriculography after myocardial infarction. Qf Med 1980; 49: 479-90.

25 Dewhurst NG, Muir AL. Comparative prognostic value of radionuclide ventriculography at rest and during exercise in 100 patients after first myocardial infarction. $\mathrm{Br}$ Heart F 1983; 49: 111-21.

26 Wackers FJ, Berger HJ, Weinberg MA, Zaret BL. Spontaneous changes in left ventricular function over the first 24 hours of acute myocardial infarction: implications for evaluating early therapeutic interventions. Circulation 1982; 66: 748-54.

27 Borer JS, Rosing DR, Miller RH, et al. Natural history of left ventricular function during one year after acute myocardial infarction. Comparison with clinical, electrocardiographic and biochemical determinations. Am $\mathfrak{F}$ Cardiol 1980; 46: 1-12.

28 Schelbert HR, Henning H, Ashburn WL, Verba JW, Karliner JS, O'Rourke RA. Serial measurements of left ventricular ejection fraction by radionuclide angiography early and late after myocardial infarction. Am $\mathcal{F}$ Cardiol 1976; 38: 407-15.

29 Spencer FC. The significance of myocardial preservation 
and subclinical myocardial infarction following coronary bypass. Ann Thorac Surg 1978; 26: 197-203.

30 Espinoza J, Lipski J, Litwak R, Donoso E, Dack S. New $Q$ waves after coronary bypass surgery for angina pectoris. Am F Cardiol 1974; 33: 221-2.

31 Sternberg L, Wisneski JA, Ullyot DJ, Gertz EW. Significance of new $Q$ waves after aortocoronary bypass surgery. Circulation 1975; 52: 1037-44.

32 Dawson JT, Hall RJ, Garcia E, Cooley DA. Myocardial infarction after coronary artery bypass (CAB) surgery [Abstract]. Circulation 1972; 46 (suppl II): II 144.

33 Raabe DS Jr, Morise A, Sbarbaro JA, Gundel WD. Diagnostic criteria for acute myocardial infarction in patients undergoing coronary artery bypass surgery. Circulation 1980; 62: 869-78.

34 Coleman RE, Klein MS, Roberts R, Sobel BE. Improved detection of myocardial infarction with Technetium $99 \mathrm{~m}$ stannous pyrophosphate and serum MB creatine phosphokinase. Am $\mathcal{F}$ Cardiol 1976; 37: 732-5.

35 Karunaratne HB, Walsh WF, Fill HR, Resnekov L, Harper PV. Technetium 99m pyrophosphate myocardial scintigraphy in patients with chest pain. Lack of diagnostic specificity [Ábstract]. $\mathcal{F}$ Nucl Med 1976; 17: 523-4.

36 Gray RJ, Shell WE, Conklin C, et al. Quantification of myocardial injury during coronary artery bypass graft. Circulation 1978; 58 (suppl I): 38-42.
37 Klein MS, Coleman RE, Weldon CS, Sobel BE, Roberts R. Concordance of electrocardiographic and scintigraphic criteria of myocardial injury after cardiac surgery. F Thorac Cardiovasc Surg 1976; 71: 934-7.

38 Bassan MM, Oatfield R, Hoffman I, Matloff J, Swan HJC. New Q waves after aortocoronary bypass surgery. Unmasking of an old infarction. $N$ Engl $\mathcal{F}$ Med 1974; 290: 349-53.

39 Aintablain A, Hamby RI, Hoffman I, Weisz D, Voleti C, Wisoff BG. Significance of new $Q$ waves after bypass grafting: correlation between graft patency ventriculogram and surgical venting techniques. Am Heart $\mathcal{f}$ 1978; 95: $429-40$.

40 Baur MR, Peterson TA, Arnar V, Gannon PG, Gobel FL. Predictors of perioperative myocardial infarction in coronary artery operation. Ann Thorac Surg 1981; 31: 36-44.

41 Langou RA, Wiles JC, Peduzzi PN, Hammond GL, Cohen LS. Incidence and mortality of perioperative myocardial infarction in patients undergoing coronary artery bypass grafting. Circulation 1977; 56 (suppl II): 54-8.

42 Chaitman BR, Alderman EL, Sheffield LT, et al. Use of survival analysis to determine the clinical significance of new $Q$ waves after coronary bypass surgery. Circulation 1983; 67: 302-9. 